\title{
Rhizoctonia solani f.sp. Sasakii Inciting Banded Leaf and Sheath Blight of Maize and their Management: An Overview
}

\author{
S.K. Singh ${ }^{1 *}$, M.B. Patel ${ }^{1}$, B.N. Thakker ${ }^{1}$, K.S. Hooda ${ }^{2}$ and Alpesh Kumar Barad ${ }^{1}$ \\ ${ }^{1}$ Main Maize Research Station, Anand Agricultural University, \\ Godhra-389001 (Panchmahals) (India) \\ ${ }^{2}$ ICAR-Indian Institute of Maize Research, PUSA Campus, New Delhi 110012 (India) \\ *Corresponding author
}

Keywords

Banded leaf and sheath blight,

Rhizoctonia solani,

Maize,

Symptomatology,

Disease cycle, Host

range,

Epidemiology,

Screening technique,

Disease management

Article Info

Accepted:

26 June 2019

Available Online:

10 July 2019

\section{Introduction}

Maize banded leaf and sheath blight (BLSB) caused by Rhizoctonia solani f.sp. sasakii (Thanatephorus cucumeris) is considered as one of the most important disease and major constraint for low yields. Banded leaf and sheath blight (BLSB) incited by Rhizoctonia solani f.sp. sasakii Exner, was first recorded on maize in Sri Lanka (Bertus, 1927). In India the disease was first recorded in the Tarai (foot hill plain areas) region of Uttar Pradesh (Payak and Renfro, 1966). Yield losses vary from 11 to 40 per cent (Singh and Sharma, 1976). The banded leaf and sheath blight pathogen is soil-borne and its occurrence has also been recorded several maize growing areas from Himachal Pradesh, Uttar Pradesh, Haryana, Punjab, Madhya Pradesh, Rajasthan (Payak and Sharma, 1981) and Gujarat. In 
view of increasing incidence of banded leaf and sheath blight of maize, the present an overview was undertaken.

Maize is miracle crop and yellow revolution is to be brought by this crop. Being Queen of cereals with highest yield potential among cereals, it can play a vital role in ensuring food and nutritional security for India and world as a whole. Major maize growing season is Kharif, which accounts for about $85 \%$ of total maize area whereas Rabi maize contributes $>25 \%$ of annual production with $<10 \%$ of total maize growing area in the country. About 112 diseases of maize have been reported so far from different parts of the world. Of these, 65 are known to occur in India. The major diseases in different agroclimatic regions are: seed rots and seedling blight, leaf spots and blights, downy mildews, stalk rots, banded leaf \& sheath blight and smuts \& rots, leading to about $15-20$ percent yield losses annually.

During the last two decades or so the banded leaf and sheath blight of maize has continued its devastating advance, causing epidemic outbreaks in maize growing countries like Bhutan, China, India, Indonesia, Nepal, the Philippines, and Vietnam, as well as in several countries in Africa and Latin America. Considerable efforts were directed to understand not only the etiology and epidemiology of the disease but also to identify host resistance, genetic nature of resistance, and exploitation of resistance sources for the development of elite cultivars. It is one of the most widespread, destructive, and versatile pathogens. It is found in most parts of the world and is capable of attacking a wide range of host plants, including maize causing seed decay, damping off, stem canker, root rot, aerial blight and seed/cob decay.

In spite of the advent of knowledge on these aspects, BLSB has still remained an Achille's heel for maize scientists all over the world. Very little progress has been achieved in the development of resistant or tolerant cultivars. One of the biggest handicaps has been the failure to locate naturally existing resistant gene sources in known maize varietal or racial complexes. Hybrids developed from tolerant inbred lines have given inconsistent level of resistance to this disease. Management of disease through chemicals, biocontrol approaches and cultural practices have still been the mainstay for minimizing the devastation in maize growing areas.

\section{The causal organism (Rhizoctonia solani)}

Banded leaf and sheath blight disease is caused by $R$. solani is one of the most widespread, destructive, and versatile pathogen found in most parts of the world and is capable of attacking a wide range of host plants, including maize causing seed decay, damping off, stem canker, rootrot, aerial blight, and seed or cob decay. It is the combination of its competitive saprophytic ability and high pathogenic potential that makes $R$. solani persistent and destructive plant pathogen (Saxena, 1997). The colonies produced by the fungus were fast growing, and formed silky white colonies on PDA medium at $28 \pm 1{ }^{\circ} \mathrm{C}$, which gradually lost their luster and became dull in appearance. The mycelium was colorless when young, but assumes brown color as it matures. Microscopic examination of hyphae revealed it as multinucleate, septate and branching atright angles. Hyphae are septate and typically constricted at the point of branching and contain dough nut shaped pore that enables nuclei, mitochondria to migrate between cells. Sclerotia were produced abundantly in culture. Sclerotia typically 1-5 $\mu \mathrm{m}$ diameter spherical and dark brown to black in color (Duggar, 1915; Reyes, 1941; Sohi et al., 1965; Singh and Sharma, 1976; Maiti, 1978 and Akhtar et al., 2009). 


\section{Distribution and economic losses}

Banded leaf and sheath blight has been reported in India, Germany, USA, Nigeria, Venezuela, Sierra Leone, Ivory Coast and England. In particular, BLSB is recognized as a serious impediment to maize production in India, China, South Asia and Southeast Asia (Sri Lanka, Indonesia, Cambodia, Bangladesh Pakistan, Nepal, Myanmar, Thailand, Laos, Vietnam, Philippines, Taiwan, Malaysia, Korea and Japan). Surprisingly, in China, yield losses close to $100 \%$ have been attributed to BLSB. This disease causes a considerable reduction of high yielding varieties. In country like India, Lal et al., (1980) have estimated in ten cultivars a loss in grain yield ranging from 23.9 to $31.9 \%$, whereas Singh and Sharma (1976) estimated $10-40 \%$ in other cultivars. Lalet al., (1985) had suggested that grain yield loss can go up to an extent of $90 \%$. In Guangxi province of China, yield losses of 87.5 and $57.8 \%$ were recorded under natural conditions in the hybrids Luyu 13 and Guiding planted at BaoQiao and Chen Xiang (Sharma, 2005). In addition to anastomosis group $R$. solaniAG-1 IA, a major pathogen of maize (Gonzalez Vera et al., 2009), Buddemeyer et al., (2004) conducted studies to estimate the damages, caused by $R$. solaniAG2-2IIIB, for different maize cultivars under German growing conditions of sugar beet-maize cropping system.

They reported that shoot fresh matter and grain yield of infested plants as compared to healthy plants were reduced up to 37 and $12 \%$, respectively. In USA, Sumner and Minton (1989), by planting maize in infested and non-infested plots with high and low inoculum levels, reported yield reduction of 42 and $8 \%$ in soils infested with high inoculum level, while the same was 17 and $1 \%$ under low inoculum level for a period of three years.

\section{Symptomatology}

The symptoms of the Banded leaf \& sheath blight are observed on all aerial parts of the maize plant except tassel. The disease manifests itself on leaf, leaf sheaths, stalks and ears as leaf \& sheath blight, stalk lesions or rind spotting and stalk breakage, clumping and cracking of styles (silk fibre), horse-shoe shaped lesions with banding of caryopses, ear rots, etc. Under natural conditions, disease appears at preflowering stage on 30 to 40 days old plants but infection can also occur on young plants which may subsequently result in severe blighting and death of apical region of growing plants. Under natural conditions, dropping blades especially the distal halves of leaves proximate to soil surface are affected. Infection spreads from leaf sheaths to the basal portion of leaves. Lesions appear as in irregular patches, similar in colour but larger in size and spread more rapidly than on leaf sheath, covering greater areas with alternating dark bands. The symptoms are more common on sheaths than on leaves. The disease appears on basal leaf sheaths as water soaked, straw colored, irregular to roundish spots on both the surfaces. A short of wave pattern of disease advancement can be seen not only on leaves but also on sheaths and husk leaves. In early stages marginal chlorosis and rotting of lamina proceed inwardly. Later as the infection becomes older numerous sclerotial bodies are also seen (Fig. 1).

The pathogen also causes elongated dark brown to black spots of lesions on the rind of the stalk under the affected sheaths. These spots coalesce together extending the lesions and covering almost an internodes. Individual lesion range in size from $2-10 \times 3-15 \mathrm{~mm}$ to those which cover the whole internodes. Sometimes these lesions are transformed into cankers and a few girdle near the nodes. Under artificial inoculation entire rind is sometimes affected, the stalk thereby 
weakened and breaks easily. The disease observed first of all, on basal part of the outermost husk leaves forwarding to sheath from which the ear emerge. The same types of lesions are found on ear but the bands are fairly prominent, giving a blackened appearance. The affected ears become brown and numerous sclerotia are observed on husks, lightly attached to the cob. Whitish mycelium and sclerotia are also seen frequently on silks between and on kernel rows and glumes (Fig. 1). The grain showed light greyish to dark brown discoloration, drastically reduced in size and wrinkled, and under severe conditions, the grain became chuffy and light in weight.

\section{Disease cycle}

Rhizoctonia solani survives in the soil and on infected crop debris as sclerotia or mycelium. Sclerotia are known to survive for several years in the soil. The fungi spread by water (flooding), irrigation, movement of contaminated soil, and plant debris. At the onset of the growing season, in response to favorable humidity and temperatures (15 to $35^{\circ} \mathrm{C}$ ), fungal growth is attracted to freshly planted host crops by chemical stimulants released by growing plant cells. The fungi infect plants, leading to characteristic symptoms on the stem, sheaths, leaves and ears. The fungi over winter as sclerotia or in infected crop debris (Fig. 2).

The primary sources of inoculum are sclerotia in the soil and grass hosts that grow in the vicinity of maize crop. Secondary spread of disease is by contact of infected leaves with parts of adjoining healthy plants. The optimum temperature for in vitro growth of the pathogen is $30^{\circ} \mathrm{C}$ and the highest level of disease is induced when $\mathrm{RH}$ is in the range of 90-100 per cent. At RH 70 per cent or lower, the disease development is negligible or absent. These conditions of relative humidity, moisture and temperature exist in maize growing areas in the month of July and August, a time when the crop is in vulnerable growth stage (Fig. 2).

\section{Host range}

The pathogen has wide host range and infects plant belonging to over 32 families in 188 genera. R. Solanif. sp. Sasakii infected in artificial inoculations a number of crop plants belonging to families Graminae, Papilionacae and Solanaceae: Paspalum scrobiculatum, Pannisetum purpureem, Setariaitalica, Panicummiliaceum, Coixlachryma-jobi, Echnochola fromentacea, Pennisetum americanum, Zeamaxicana,Zea mays, Oryza sativa, Saccharum officinarum, Sorghum bicolor, Arachis hypogea, Glycine max, Pisum sativum, Vigna radiate and Lycopersicum esculentum. Rice and maize isolates are, however, indistinguishable on the basis of cross inoculation tests, host range, virulence, number of nuclei per hyphal cell, and other morphological characters including pathogenicity. Comparison studies of rice, maize, sugarcane and sorghum isolates revealed that maize and rice are similar than those isolates of sugarcane and sorghum (Saxena, 1997).

\section{Epidemiology}

Population of sclerotia in ploughed field is higher at $12 \mathrm{~cm}$ depth rather than in upper layers and the sclerotia buried deep in soil have better buoyancy and germinability (Dash, 1985). In undisturbed soil, sclerotia are present upto $2 \mathrm{~cm}$ depth (Roy, 1980). The viability of sclerotia is greatly influenced by environmental and soil conditions. The primary source of inoculums are the sclerotia in soil or in infected host debris, and the active mycelium on the other grass hosts that grow in the vicinity of maize plant in the field. Sclerotia which survive on plant debris 
often come up on the soil surface during field preparation and other operations. They come in contact with newly planted seedlings/plants and cause infection. The germinated sclerotia come in contact with lower leaf sheaths or drooping leaves touching the soil surface. Infection progresses upward in bands killing the tissues in advance; it extends to distal half of the leaf lamina exhibiting buffwhite mycelia growth in patches with $48-72 \mathrm{hr}$ of infection. The primary inoculums become more active during pre-flowering stage (30-40 days old plant) which occurs in late July and early August in North India as well as plains.

Seeds are not considered to be source of inoculums and may not play a major role in severe disease outbreaks. The infection continues to middough stage covering the entire plant including the ear but not the tassel. If ear infection occurs at a late stage, germination of seed is adversely affected resulting in seed rot and seedling blight. Secondary spread is due to contact of healthy plants with infected leaves/sheaths or viceversa. The sclerotia formed on infected plant organs on the soil surface together with infected host debris serve as a source of primary inoculums for maize and other host crops. Secondary spread by basidiospores has not been observed in maize crop. Though the pathogen produces distinct horseshoe shaped lesions on seed, the seed inoculums is of little importance in areas where disease is already known to occur. The pathogen is soil-borne and also survives on a large number of cultivated and wild plants.

The optimum temperature for in vitro growth of the pathogen is $30^{\circ} \mathrm{C}$ and the highest level of disease is induced when the relative humidity $(\mathrm{RH})$ is in the range of $90-100$ per cent. At RH 70 per cent or below, disease development is negligible or absent. High relative humidity and rainfall largely influence the spread of the disease. Studies on the meteorological factors in relation to disease development revealed that an optimum temperature of about $28^{\circ} \mathrm{C}$ was essential for infection, disease development and subsequent spread of the pathogen. Relative humidity affected the progress of the disease development to a large extent. High relative humidity ( 88 to 90 per cent) in the first two weeks of infection favored rapid disease progress but $\mathrm{RH}$ below 70 per cent checked the development and spread of the disease. Similarly, rainfall over $100 \mathrm{~mm}$ in the first two weeks of infection favored early infection and disease development (Ahuja and Payak, 1981).

\section{Screening techniques}

\section{Multiplication of inoculums}

The most convenient method of multiplication is on whole barley grains with intact husks; soaking the grains in water for 24-36 hrs after thorough washing in running tap water. The soaked grains $(40 \mathrm{~g})$ are dispensed in $250 \mathrm{ml}$ Erlenmeyer flasks after removing excess water and plugged with cotton and aluminum foil tightly. The flasks are autoclaved at $15 \mathrm{lb}$ psi for 30 minutes. Before the second sterilization is attempted $24 \mathrm{hrs}$ after the first one, each flask should be shaken to avoid formation of clotting/caking. The grain medium is inoculated with actively growing culture on PDA. One to two discs may be inoculated in each flask. Good mycelia growth has also been reported by seeding 5 $\mathrm{ml}$ actively growing homogenized culture suspension in sterile water. The flasks are incubated at $28^{\circ} \mathrm{C}$ for $7-10$ days. During incubation, the grains in flasks should also be shaken to provide uniform fungal growth on all grains. This grain culture can be used immediately for inoculation. Uniform mycelia growth is favored by dark conditions whereas sclerotial production predominates in cultures incubated in light. 


\section{Inoculation technique}

Inoculation should be carried out during wet season on 30 to 45 days old plants with grain culture (using four grains) inserted between stalk and sheath at second or third internodal level from soil. Grains placed at junction of sheath and leaf can also create optimum disease level and remain secure even under strong wind conditions or heavy rains (Ahuja and Payak, 1978).

\section{Disease assessment}

A graded 1 to 9 disease scoring scale has been developed taking into account the entire range of symptoms, viz., number of sheaths affected, proportion of prematurely dead plants, stem breakage, rotted ears, and lesions on the stalk, etc. Record of disease intensity is made about 45 days after inoculation on the basis of the following scale given in Table 1.

\section{Disease management}

The pathogen is soil-borne, drenching with fungicides is expensive and impractical. Development of resistant cultivar is more ideal to suit the strategy but it can be possible with the availability of host resistance. Isolates of Pseudomonas fluorescens were isolated and used as biocontrol agent as the bacterium was reported to suppress soil-borne diseases caused by fungal pathogens (Weller, 1988). Efficacy of chemicals (viz, Propaconazole, $0.1 \%$, and Carbendazim, $0.05 \%$ ), by applying as foliar sprays at 30,40 and 50th day of planting, alone or in combinations. Effectiveness of Propaconazole was markedly observed when the chemical was applied at initial stages at $30^{\text {th }}$ or $40^{\text {th }}$ day after planting and the second spray at 10 days after first. Foliar sprays of Carbendazim showed the ineffectiveness against BLSB (Saxena, 2002). On in vitro evaluation, three often used fungicides, namely Bavistin,
Rhizolex, and Thiophenate M, have shown absolute control of mycelial growth with $100 \%$ inhibition. It is, therefore, envisaged that under field conditions a high level of control of BLSB could be achieved using these three fungicides (Sharma et al., 2002). The antibiotic Validamycin was able to give only $56.3 \%$ inhibition at $30 \mathrm{ppm}$.

Rhizoctonia solaniis parasitized by the number of fungus species Trichoderma, Gliocladium, and Laetisaria, bacteria (Pseudomonas fluorescence), and nematodes (Aphelenchus avenae). Reduction in disease incident of BLSB was observed when $P$. fluorescence was used in seed and soil treatment and in foliar application (Meena et al., 2003). Seed treatment and soil application of this antagonist not only reduces the disease to more than $50 \%$, but additionally Sharma $e t$ al., (2002) recorded consequent increase in grain yield approximately 1.4 times of the yield of the control. Another biocontrol agent, named Trichoderma harzianum, also provided as high as $68 \%$ of inhibition of the mycelia of $R$. solani, under in vitro conditions (Sharma $e t$ al., 2002). Formulations of antibiotic Validamycin also show good control against BLSB (Jiang et al., 1991) but due to high cost, Validamycin does not appear to be profitable proposition (Sharma et al., 2002).

Different genotypes were evaluated under All India Coordinated Research Project on Maize at various centres on over country using artificial inoculation techniques. Few genotypes were found as resistant HKI 1105 and DQL 2105-1, whereas the following genotypes were grouped as moderately resistant CM 117-3-2-1-1-12-1, CML 446, DMSC 20, DMSC 1, DMSC6, HKI 164-D-33-2, HKI-Talar, HKI-2-6-2-4 (1-42)-4, HYD05R/204-1, JCY2-7-2-1-1-B-1-2-1-1, POBLAC61C4, SHD-1ER6, EI 670, EI 561, BML 13, BML 8, CM 119, CM 500, CML 451Q, CML 117-3-4-1-1-4-1, CML 165, 
CML 175, CML 321, HKI-164-7-4-2, HKI 191-1-2-5, HKI-484-5, JCY2-2-4-1-1, LM-5, P72c1xbrasil 1177-2, TS2TR1107, V334, DQL 2006, DQL-2008-1, DQL 2010, DQL
2028, DQL 2031, DQL 2048, DQL 2054, DQL 2071, DQL 2113 and DQL 2104 (Annual Report, 2014-15).

Table.1

\begin{tabular}{|c|c|c|c|}
\hline $\begin{array}{l}\text { Rating } \\
\text { scale }\end{array}$ & Degree of infection (per cent DLA) & $\begin{array}{c}\text { Percent } \\
\text { disease } \\
\text { index (PDI) }\end{array}$ & Disease reaction \\
\hline 1.0 & $\begin{array}{l}\text { Disease on one leaf sheath only; few small, non-coalescent lesions } \\
\text { present }(\leq 10 \%)\end{array}$ & $\leq 11.11$ & \multirow{3}{*}{$\begin{array}{l}\text { Resistant }(\mathrm{R}) \\
(\text { Score: } \leq 3.0) \\
(\mathrm{DLA}: \leq 30 \%) \\
(\mathrm{PDI}: \leq 33.33)\end{array}$} \\
\hline 2.0 & Disease on two sheaths; lesions large and coalescent (10.1-20\%) & 22.22 & \\
\hline 3.0 & $\begin{array}{l}\text { Disease up to four sheaths; lesions many and always coalescent } \\
(20.1-30 \%)\end{array}$ & 33.33 & \\
\hline 4.0 & $\begin{array}{l}\text { As in disease rating symptoms of } 3.0,+ \text { rind discolored with small } \\
\text { lesions }(30.1-40 \%)\end{array}$ & 44.44 & \multirow{2}{*}{$\begin{array}{c}\text { Moderately resistant (MR) } \\
\text { (Score: } 3.1-5.0) \\
\text { (DLA: } 30.1-50 \%) \\
\text { (PDI: } 33.34-55.55)\end{array}$} \\
\hline 5.0 & $\begin{array}{l}\text { Disease on all sheaths except two internodes below the ear ( } 40.1- \\
50 \%)\end{array}$ & 55.55 & \\
\hline 6.0 & $\begin{array}{l}\text { Disease up to one internode below ear shoot; rind discoloration on } \\
\text { many internodes with large depressed lesions }(50.1-60 \%)\end{array}$ & 66.66 & \multirow{2}{*}{$\begin{array}{l}\text { Moderately susceptible } \\
\text { (MS) } \\
\text { (Score: } 5.1-7.0) \\
\text { (DLA: } 50.1-70 \%) \\
\text { (PDI: } 55.56-77.77 \text { ) }\end{array}$} \\
\hline 7.0 & $\begin{array}{l}\text { Disease up to the internodes bearing the ear shoot but shank not } \\
\text { affected }(60.1-70 \%)\end{array}$ & 77.77 & \\
\hline 8.0 & $\begin{array}{l}\text { Disease on the ear; husk leaves show bleaching, bands and } \\
\text { cracking among themselves as also silk fibers; abundant fungal } \\
\text { growth between and on kernels; kernel formation normal except } \\
\text { being lusterless; ear size less than normal; some plants } \\
\text { prematurely dead (70.1-80\%) }\end{array}$ & 88.88 & \multirow[t]{2}{*}{$\begin{array}{l}\text { Susceptible }(\mathrm{S}) \\
\text { (Score: }>7.0) \\
\text { (DLA: }>70 \%) \\
\text { (PDI: > 77.77) }\end{array}$} \\
\hline 9.0 & $\begin{array}{l}\text { In addition to disease rating symptoms of } 8.0 \text {, shrinkage of stalk; } \\
\text { reduced ear dimensions, wet rot and disorganization of ear; kernel } \\
\text { formation absent or rudimentary; prematurely dead plants } \\
\text { common; abundant sclerotia production on husk leaves, kernels, } \\
\text { ear tips and stalk fibres }(>80 \%)\end{array}$ & 99.99 & \\
\hline
\end{tabular}

Fig.1 Banded leaf and sheath blight on lower maize leaves and sheath and large brown sclerotia produced by Rhizoctonia solani on infected leaves and stem
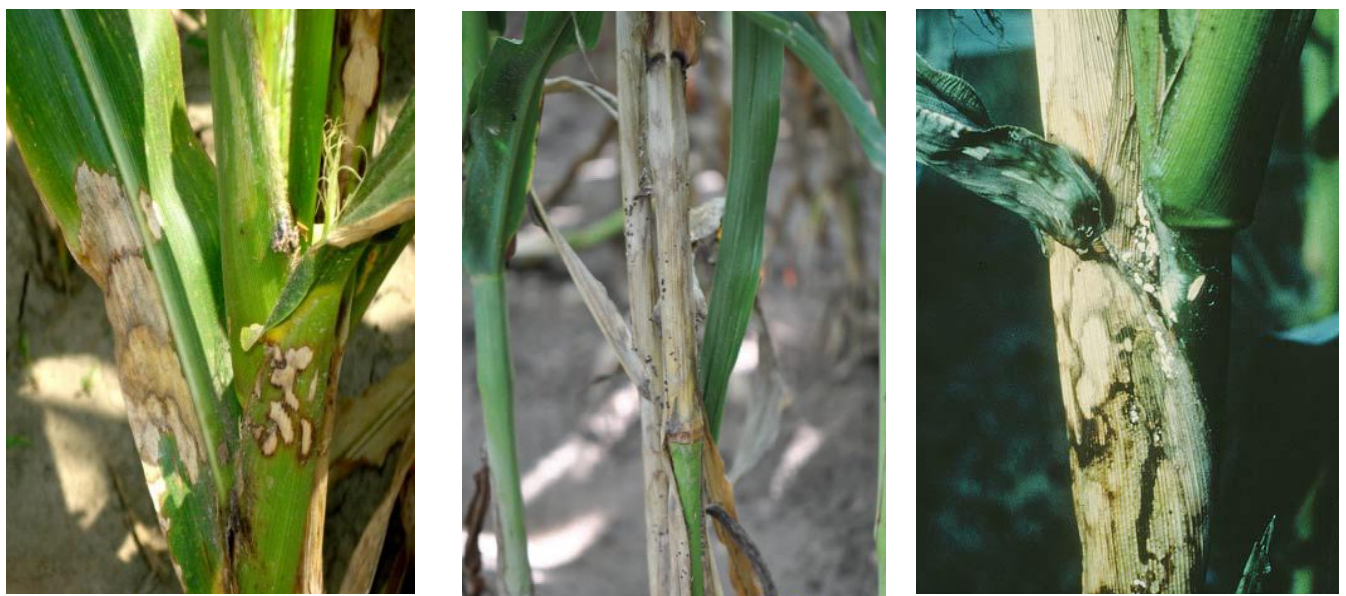
Fig.2 Disease cycle of Rhizoctonia solani (Banded leaf and sheath blight of maize)

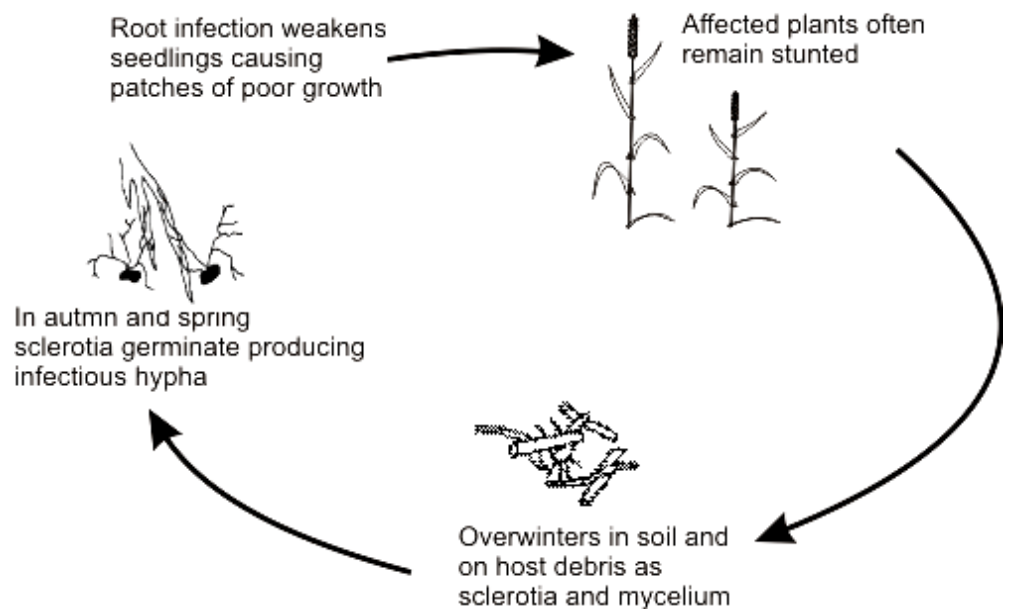

Cultural practices for $R$. solani, selection of a well-drained field and planting on raised beds are important aspects to avoid contact of water with seeds and faster growth of seedlings. Composting of hardwood on Rhizoctonia infested soil has been found to reduce disease severity, apparently by promoting the growth of Trichoderma and other antagonistic microorganisms (Hoitink, 1980).

\section{References}

Ahuja, S.C. and Payak, M.M. 1978. A field inoculation technique for evaluating maize germplasms to baned leaf and sheath blight. Indian Phytopathology, 34: 34-37.

Ahuja, S.C. and Payak, M.M. 1981. Relationship of relative humidity and temperature level with the development of leaf and sheath blight of maize. Z. Pflakranth. Pflschutz., 88: 265-268.

Akthar, J., Kumar Jha, V. and Lal, H.C. 2009. Occurrence of Banded Leaf and Sheath blight of Maize in Jharkand with Reference to Diversity in Rhizoctonia solani. Asian Journal of Agricultural Sciences., 1 (2): 3235.

Annual Report, 2014-15. ICAR-Indian Institute of Maize Research, PUSA Campus, New Delhi 110012 (India) pp. 27-29.

Bertus, L.S. 1927. A sclerotial disease of maize
(Zea mays L.) due to Rhizoctonia solani Kuhn. Yearbook, Department of Agriculture, Ceylon, 44-46.

Bertus, L.S. 1927. A sclerotial disease of maize (Zea mays L.) due to Rhizoctonia solani Kuhn. Yearbook, Department of Agriculture, Ceylon, 44-46.

Buddemeyer, J., Pfahler, B., Peterson, J. and Marlander, B. 2004. Genetic variation in susceptibility of maize to Rhizotonia solani (AG2-2IIIB) symptoms and damage under field conditions in Germany. J. of Plant Diseases and Protect., 111: 521-533.

Dash, S.N. 1985. Studies on the epidemiology and leaf and sheath blight of maize. Indian Mycological Research, 23: 53-56.

Duggar, B.M. 1915. Rhizoctonia crocorum (Pres.) D.C. and $R$. solani Kuhn (Corticium vagum $\mathrm{B}$ and C) with notes on other spices. Annual Mel. Bot. Gard., 2: 403-458.

González-Vera, A.D., Bernardes-de-Assis, J., Zala, M., McDonald, B.A., Correa-Victoria, F., Graterol-Matute, E.J. and Ceresini, P.C. 2009. Divergence between sympatric riceand maize-infecting populations of RhizoctoniasolaniAG-1 IA from Latin America. Phytopathol., 100: 172-182.

Hoitink, H.A.J. 1980. Composted bark a light weight growth medium with fungicidal properties. Plant Dis., 64: 142-147.

Jiang, H.L., Ding, X. and Ma, H. 1991. The occurrence and chemical control of maize sheath blight (Rhizoctonia solani) in Ragao 
of Jiangsu. Plant Prot., 6: 11-12.

Lal, S.,Baruah, P. and Butchaiah, K. 1980. Assessment of yield losses in maize cultivars due to banded leaf sclerotial disease. Indian Phytopathol., 29: 129-132.

Lal, S.,Butchaiah, K. and Baruah, P. 1985. Comparative efficacy of some fungicides and antibiotics in control of banded sclerotial disease of maize. Pesticides, 19: 17-19.

Maiti, S. 1978.Two ear rots of maize from India. Plant Disease Report., 62: 1074-1076.

Meena, R.L., Rathore, R.S. andMathur, K. 2003. Efficacy of bio-control agents against Rhizoctonia solani f.sp sasakii causing banded leaf and sheath blight of maize. $J$. of Mycol. Plant Pathol., 33 (2): 310-312.

Payak, M. M. and Sharma, R. C., 1981. Disease and pest situation in high yielding hybrids and composites of maize with special reference to India. A review of pest, diseases and weed complexes in high yielding varieties in Asia and Pacific. F. A. O. Regional office, Bangkok, Thailand. pp. 84-89.

Payak, M.M. and B.L. Renfro 1966. Diseases of maize new to India. Indian Pytopath. Soc. Bull. 3, IARI, New Delhi. pp. 14-18.

Reyes, G.M. 1941. Notes on diseases affecting maize in Philippines. Journal of Agriculture, 12: 61-69.

Roy, A.K. 1980. Survival of sclerotia of Rhizoctoniaat different soil depths. International Rice Research Newsletter,5: 12.

Saxena, S.C. 1997. Banded leaf \& Sheath blight of maize. In: Agnihotri, V.P.; Sarbhoy, A.K. and Singh, D.V. eds. Management of threatening plant diseases of national importance. Malhotra Publishing House, New Delhi, pp. 31-50.
Saxena, S.C. 2002. Bio-Intensive Integrated disease management of banded leaf and sheath blight of maize, pp. 380-388. In: Proceed of 8th Asian Regional Maize Workshop: New Technologies for the New Millennium, Bangkok, Thailand.

Sharma, R.C. 2005. Banded leaf and sheath blight (Rhizoctonia solani f. sp sasakii) of maize, pp159- 171. In: Stresses of maize in Tropics. Zaidi PH, Singh NN eds.

Sharma, R.C.,Vasal, S.K., Gonzalez, F.,Batsa, B.K. and Singh, N.N. 2002. Redressal of banded leaf and sheath blight of maize through breeding, chemical and biocontrol agents, In: Proceed of the 8th Asian Regional Maize Workshop: New Technologies for the New Millennium, Bangkok, Thailand. pp. 391-397.

Singh, B.M. and Sharma, Y.R. (1976). Evaluation of maize germplasm to banded sclerotial disease and assessment of yield loss. Indian Phytopathology. 29: 129-132.

Singh, B.M. and Sharma, Y.R. 1976. Evaluation of maize germplasm to banded sclerotial disease and assessment of yield loss. Indian Phytopathol., 29: 129-132

Sohi, H.S., Sharma, S.L and Verma, B.R. (1965). Diseases of maize occurring in HP. Proceeding of Maize Improvement Conference, New Delhi, pp: 122-124.

Sumner, D.R. and Minton, N.A. 1989. Crop losses in corn induced by RhizoctoniasolaniAG22 and nematodes. Phytopathol., 79: 934941.

Weller, D.M. 1988. Biological control of soilborne plant pathogens in the rhizosphere with bacteria. Ann. Rev. Phytopathol., 26: 379-407.

\section{How to cite this article:}

Singh, S.K., M.B. Patel, B.N. Thakker, K.S. Hooda and Alpesh Kumar Barad. 2019. Rhizoctonia solani f.sp. Sasakii Inciting Banded Leaf and Sheath Blight of Maize and their Management: An Overview. Int.J.Curr.Microbiol.App.Sci. 8(07): 2858-2866. doi: https://doi.org/10.20546/ijcmas.2019.807.356 